\title{
DISTRIBUICGÃO ESPACYOTEMPORAL DOS PARÂMETROS ABIÓTICOS E BIÓTICOS EM UM ESTUÁRIO AMAZÔNICO (BRASIL)
}

\section{Temporal space distribution of abiotic and biotic parameters in an amazon estuary (Brazil)}

\author{
Arielly Siqueira dos Santos ${ }^{1}$, Pedro Henrique Campos Sousa ${ }^{2}$, Nuno Filipe Alves Correia de Melo ${ }^{3}$, \\ Karina Ferreira Castro ${ }^{4}$, José Almir Rodrigues Pereira ${ }^{5}$, Maria de Lourdes Souza Santos ${ }^{6}$ \\ ${ }^{1}$ MSc em Aquicultura e Recursos Aquáticos Tropicais, pela Universidade Federal Rural da Amazônia. \\ E-mail: ariellysiqueiradossantos@gmail.com \\ ${ }^{2}$ MSc em Aquicultura e Recursos Aquáticos Tropicais, pela Universidade Federal Rural da Amazônia \\ E-mail: pedrophhenrique13@gmail.com \\ ${ }^{3}$ Professor do Instituto Sócio Ambiental e dos Recursos Hídricos, Universidade Federal Rural da Amazônia. \\ E-mail:nuno.melo@ufra.edu.br \\ ${ }^{4}$ Professora do Instituto Federal do Pará, campus Tucuruí. E-mail: kfcmesquita@gmail.com \\ ${ }^{5}$ Professor da Faculdade de Engenharia Sanitária e Ambiental, Universidade Federal do Pará. \\ E-mail: rpereira@ufpa.br \\ ${ }^{6}$ Professora do Instituto Sócio Ambiental e dos Recursos Hídricos, Universidade Federal Rural da Amazônia. \\ E-mail: mdelssantos@yahoo.com.br
}

\section{RESUMO}

O objetivo deste trabalho foi avaliar a distribuição dos parâmetros abióticos (temperatura, salinidade, $\mathrm{pH}$, oxigênio dissolvido, taxa de saturação de oxigênio dissolvido, material em suspensão, $\mathrm{N}$-amoniacal, nitrito, nitrato, fosfato e silicato) e biótico (clorofila $a$ ) em relação aos períodos climáticos da região Amazônica, no estuário Guajará-Mirim, localizado em Vigia, no Pará. As coletas de água para análises dos parâmetros abióticos e biótico ocorreram nos meses de setembro e novembro de 2011 e janeiro, março, maio e julho de 2012. A distribuição dos parâmetros abióticos e clorofila a no estuário de Guajará-Mirim é influenciada pelos períodos de maior e menor pluviosidade, fato também observado pela análise de componentes principais. A taxa de saturação do oxigênio dissolvido no período de estudo classificou a área como zona de baixa saturação a saturada, sem apresentar sinais de zona de poluição, e, além disso, com o valor médio do oxigênio dissolvido acima do valor estabelecido pelo Conama $n^{\circ} 357 / 2005$, para a classificação dos corpos de água. Ao mesmo tempo que o $\mathrm{N}$-amoniacal esteve em sua maioria acima do valor estabelecido por essa referida resolução, junto com as concentrações de nitrato, o que indica haver necessidade de um monitoramento mais detalhado para avaliar as fontes difusas de poluição existentes nesse

Recebido em: 15/08/2019

Aprovado em: 29/05/2020

Publicado em: 30/08/2020 
estuário. De posse dessas informações, poder-se-á propor medidas mitigadoras para manter a qualidade da água nesse ambiente tão importante para a população local.

Palavras-chave: temperatura, salinidade, clorofila $a$, nitrato, Guajará-Mirim.

\begin{abstract}
The objective of this work was to evaluate the distribution of abiotic parameters (temperature, salinity, $\mathrm{pH}$, dissolved oxygen, dissolved oxygen saturation rate, suspended material, N-ammoniacal, nitrite, nitrate, phosphate, and silicate) and biotic (chlorophyll a) in relation to the climatic periods of the Amazon region in the Guajará-Mirim estuary, which is located in Vigia, Pará. Water collection for the analysis of abiotic and biotic parameters occurred in the months of September and November of 2011 and January, March, May, and July of 2012. The distribution of abiotic and chlorophyll a parameters in the Guajará-Mirim estuary is influenced by periods of both greater and lesser rainfall, which is also indicated by the analysis of the main components. The saturation rate of dissolved oxygen in the study period classified the area as a zone of low saturation without a pollution zone. In addition, the average value of dissolved oxygen for this area exceeded the value established by Conama $n^{\circ} 357 / 2005$ for the classification of bodies of water. The findings revealed that the majority of $N$-ammoniacal and nitrate concentrations also exceeded this value, which indicates the need for more detailed monitoring to assess the diffuse sources of pollution in this estuary. With this information, mitigation measures can be proposed to maintain the water quality in this environment, which is crucial for the local population.
\end{abstract}

Keywords: temperature, salinity, chlorophyll a, nitrate, Guajará-Mirim.

\title{
INTRODUÇÃO
}

Os ecossistemas estuarinos apresentam elevada importância biológica, socioeconômica, alta taxa de produtividade primária e biomassa tanto dos produtores primários como dos consumidores. A capacidade de renovação periódica de suas águas faz dos estuários ecossistemas locais onde ocorrem intensas transformações da matéria orgânica (PereiraFilho et al., 2003).

Os fluxos dos rios através dos estuários desempenham papel significativo na distribuição local de nutrientes, introduzindo diferentes formas de nitrogênio orgânico e inorgânico na zona eufótica em áreas de plataforma continental (Metzler et al., 1997). Esses rios podem trazer grandes quantidades de nutrientes de origem natural e antrópica (Troussellier et al., 2004). A ação antropogênica nesses ecossistemas tem alterado a dinâmica natural do nitrogênio e do fósforo e, como resultado, a mobilização desses elementos tem acelerado seu fluxo para águas costeiras, o que pode causar sua eutrofização (Huang; Huang \& Yue, 2003).

O conhecimento das variáveis físico-químicas, biológicas e hidrográficas, em escalas temporal e espacial, permite a avaliação da qualidade ambiental do sistema, sua variabilidade e tendências. Além disso, essas informações constituem a base para a avaliação da capacidade de suporte do ambiente para diversas atividades (Penney; Mackenzie \& Mills, 2001), entre elas a atividade pesqueira. 
Na mesorregião do nordeste do estado do Pará, a cidade de Vigia, distante $93 \mathrm{~km}$ de Belém, há um importante estuário, o do rio Guajará-Mirim (Lira et al., 1989), que se destaca pela importante atividade pesqueira. Parte da produção é exportada para outros municípios, inclusive Belém, outra é consumida pelos moradores da localidade. O município é considerado um dos mais antigos do estado do Pará, apresenta clima equatorial do tipo Af, segundo a classificação de Köppen, e a precipitação é relativamente elevada, com cerca de $2.770 \mathrm{~mm}$, sendo os primeiros seis meses do ano os mais chuvosos (Governo do Pará, 2011).

O estuário do Guajará-Mirim possui grande extensão de comprimento (aproximadamente $45 \mathrm{~km}$ ), banhando as localidades de Porto Salvo, São Raimundo de Borralhos e ao sul do município de Colares. Possui fluxo diário de embarcações artesanais e industriais e uma urbanização acentuada na sua margem direita, despejando diariamente os mais variados resíduos domésticos na rede de esgoto, que, posteriormente, são levados para esse ambiente sem qualquer tratamento prévio (Lima et al., 2015).

Os estudos sobre a influência da maré e da sazonalidade na área do estuário GuajaráMirim em Vigia/PA são escassos, o que motivou o desenvolvimento deste trabalho, no qual se avaliou a influência desses fenômenos na distribuição dos parâmetros abióticos e clorofila $a$. Essa pesquisa servirá de subsídio para outras questões, como tomada de decisão sobre tratamento sanitário, manejo, gestão e monitoramento do referido estuário.

\section{MATERIAL E MÉTODOS}

Os pontos de coleta foram distribuídos cobrindo quatro áreas estratégicas do estuário Guajará-Mirim e a posição exata de cada ponto foi obtida com o auxílio de um GPS (Global Positioning System) da marca Garmin. Os pontos P1 e P2 estão localizados em uma área mais interna, o ponto P3 está localizado em frente à cidade e o ponto P4 é uma área mais externa do estuário (Figura 1).

Figura 1 - Mapa de localização dos pontos de coletas de amostras de água

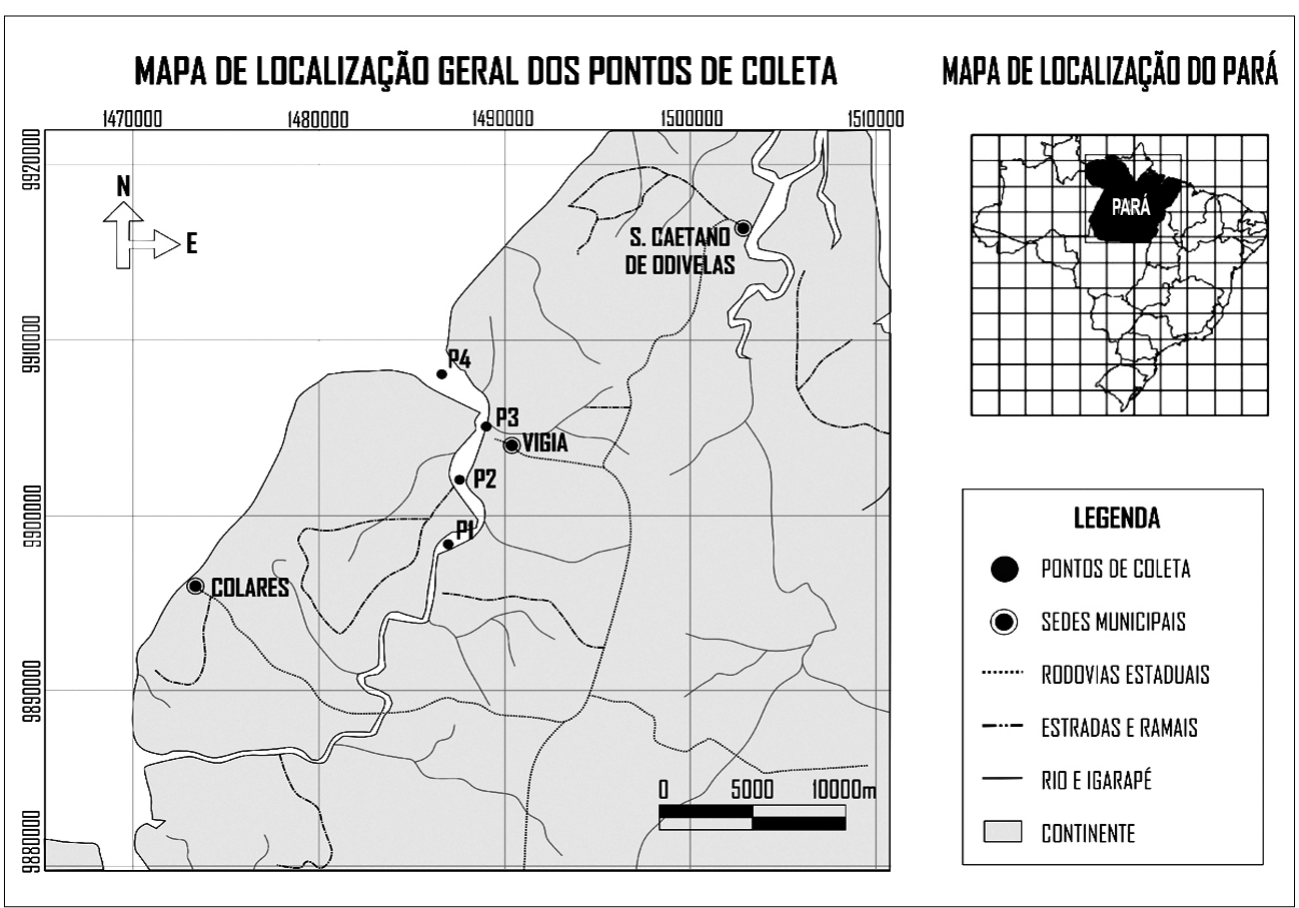


O delineamento amostral foi realizado para ter uma visão das variações na qualidade da água tanto para os parâmetros abióticos quanto para a clorofila $a$, durante o período considerado de maior pluviosidade (janeiro, março e maio de 2012) e de menor pluviosidade (setembro e novembro de 2011 e julho de 2012), em função da baixa-mar e preamar, durante a maré de sizígia, com total de 48 amostras de água.

Os dados de pluviosidade em milímetros da média histórica (1982-2012) e do período de coleta estabelecido neste trabalho foram obtidos na Agência Nacional de Águas (Ana).

As coletas de água para as análises de salinidade, $\mathrm{pH}$, temperatura, oxigênio dissolvido, taxa de saturação do oxigênio dissolvido, fosfato, nitrato, nitrito, silicato, N-amoniacal e clorofila $a$ foram feitas com a utilização de uma garrafa de Van Dorn de $5 \mathrm{~L}$, nos $50 \mathrm{~cm}$ de lâmina de água. Os dados de salinidade, $\mathrm{pH}$ e temperatura foram obtidos no momento da coleta, com a utilização de uma sonda multiparamétrica da marca Hanna. Os sólidos em suspensão foram medidos com equipamentos da marca Hach (DR 2500). Para as demais análises, as amostras de água foram acondicionadas em garrafas de polietileno de um litro, guardadas e transportadas para o Laboratório de Química Ambiental da Universidade Federal Rural da Amazônia.

O método utilizado para a determinação do teor do oxigênio dissolvido foi o de Winkler, descrito em Strickland e Parsons (1972). A taxa de saturação do oxigênio dissolvido foi obtida com a utilização da International Oceanographic Tables (Unesco, 1973), por meio dos dados obtidos de temperatura, salinidade e oxigênio dissolvido. As concentrações do fosfato, nitrato, nitrito e silicato foram determinadas segundo a metodologia descrita em Grasshoff, Ehrhardt e Kremling (1983) e filtradas com filtros GF/F de 0,45 $\mu \mathrm{m}$. A concentração do N-amoniacal foi medida pelo método de Nessler, descrito no manual Hach do aparelho DR/2010. Para determinação da concentração de clorofila $a$ foi seguida a metodologia descrita em Teixeira (1973).

Os dados abióticos e de clorofila $a$ foram analisados por métodos de estatística descritiva e da análise de componentes principais. Para melhor detecção das relações não lineares, os dados foram transformados em raiz cúbica ou log de $(X+1)$ (Legendre \& Legendre, 1998). Com isso, a análise de componentes principais foi aplicada sobre uma matriz de correlação, e os eixos fatoriais analisados foram aqueles que apresentaram seus valores significativamente mais elevados do que os produzidos pelas matrizes da mesma dimensão quando permutados 10.000 vezes (Peres-Neto; Jackson \& Somers, 2003, 2005). Ambas as análises foram realizadas com o PAST (Hammer; Haper \& Ryan, 2001).

O gráfico de box plot foi utilizado, pois permitiu uma comparação visual das distribuições das variáveis durante os períodos de menor e maior pluviosidade. Nesse gráfico, a altura das caixas representa o desvio padrão da média; o ponto central, a média e as extremidades das duas linhas, os valores máximo e mínimo.

Os dados abióticos e clorofila $a$ foram comparados à Resolução n ${ }^{0} 357$, de 2005, do Conselho Nacional do Meio Ambiente (Conama), que dispõe sobre a classificação dos corpos de água no território nacional (Brasil, 2005).

\section{RESULTADOS}

Os dados para o período em estudo da média mensal de pluviosidade durante os períodos considerados de maior e de menor pluviosidade da região oscilaram de 84,10 
mm (novembro de 2011) a 806,45 mm (março de 2012), respectivamente, conforme mostrado na Figura 2.

A temperatura da água teve o valor mínimo de $26,76{ }^{\circ} \mathrm{C}$, detectado no ponto $\mathrm{P}_{4}$ na área mais externa do estuário, durante a preamar, ocorrida em janeiro de 2012. Enquanto o maior valor foi de $30,88^{\circ} \mathrm{C}$, observado no ponto $\mathrm{P}_{3^{\prime}}$, também na preamar, em setembro de 2011. Foi possível observar que os maiores valores de temperatura (Figura 3a) ocorreram durante o período de menor pluviosidade (média de $29,62^{\circ} \mathrm{C}$ ) e os menores, no de maior pluviosidade (média de $28,17^{\circ} \mathrm{C}$ ).

Figura 2 - Distribuição da média mensal da pluviosidade no estuário Guajará-Mirim

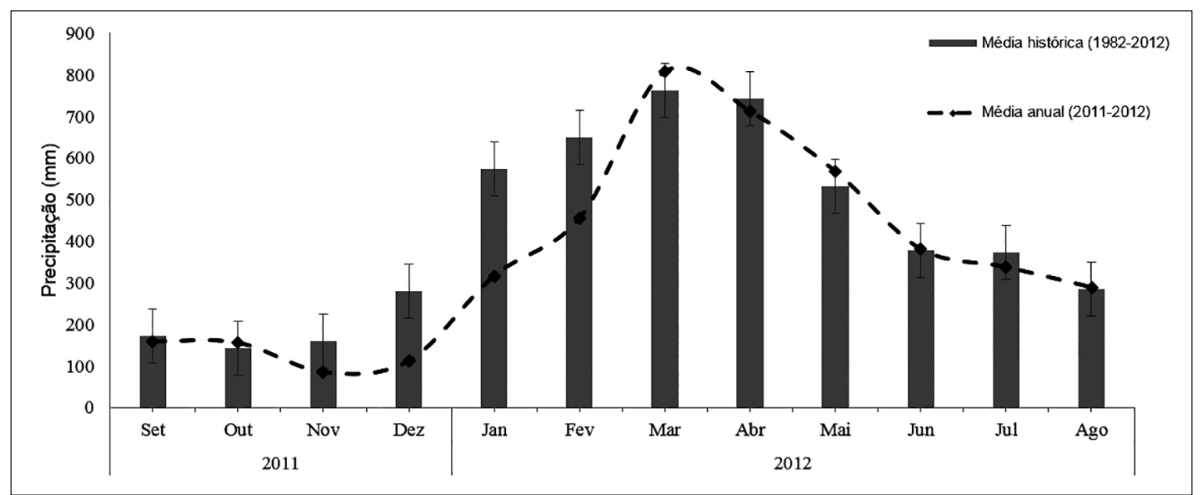

Fonte: Agência Nacional de Águas (2011).

Figura 3 - Box plot dos valores médios, mínimos e máximos de: a) temperatura, b) salinidade, c) clorofila $a$, d) sólidos em suspensão, e) nitrato e f) silicato, com os dados obtidos no estuário Guajará-Mirim, durante as coletas realizados nos meses considerados de menor pluviosidade (setembro e novembro de 2011 e julho de 2012) e de maior pluviosidade (janeiro, março e maio 2012) para a região
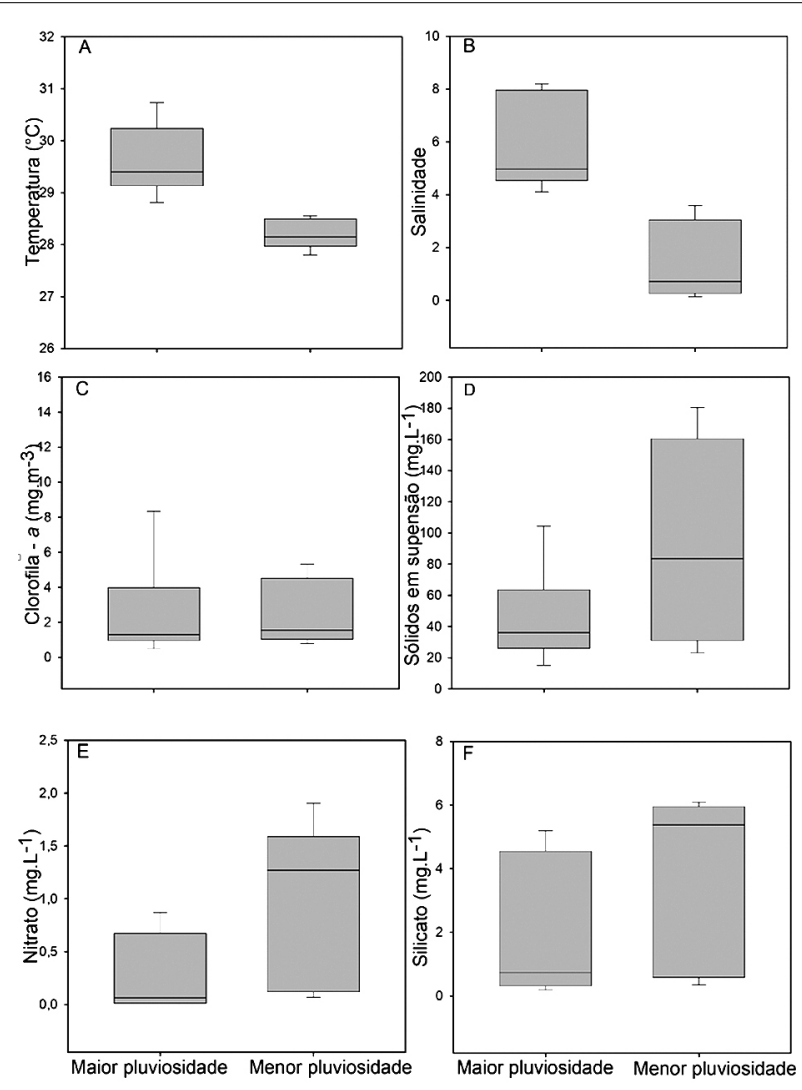

A salinidade é mencionada na legislação ambiental para enquadrar os ambientes hídricos nas classes citadas na Resolução Conama n 357/2005, na qual se caracteriza o tipo 
de água devido à quantidade de sais ali presentes: águas doces - salinidade igual ou superior a 0,5; águas salobras - águas com salinidade superior a 0,5 e inferior a 30; águas salinas - igual ou superior a 30. As águas do estuário do rio Guajará-Mirim se enquadram na Classe 1 das águas salobras.

A distribuição de salinidade teve variações expressivas nos períodos estudados. $\mathrm{O}$ menor valor $(0,11)$ foi detectado no período de maior pluviosidade, no ponto $\mathrm{P}_{4}$, na preamar em março de 2012. Enquanto o maior valor de salinidade foi de 8,42, também no ponto $\mathrm{P}_{4^{\prime}}$ em novembro de 2011, durante a baixa-mar (Figura 4). Os maiores valores da média de salinidade (Figura $3 b$ ) também foram detectados no período de menor pluviosidade, o que coincidiu com os maiores valores de temperatura.

Figura 4 - Distribuições dos valores de salinidade nos pontos de coletas durante o período estudado

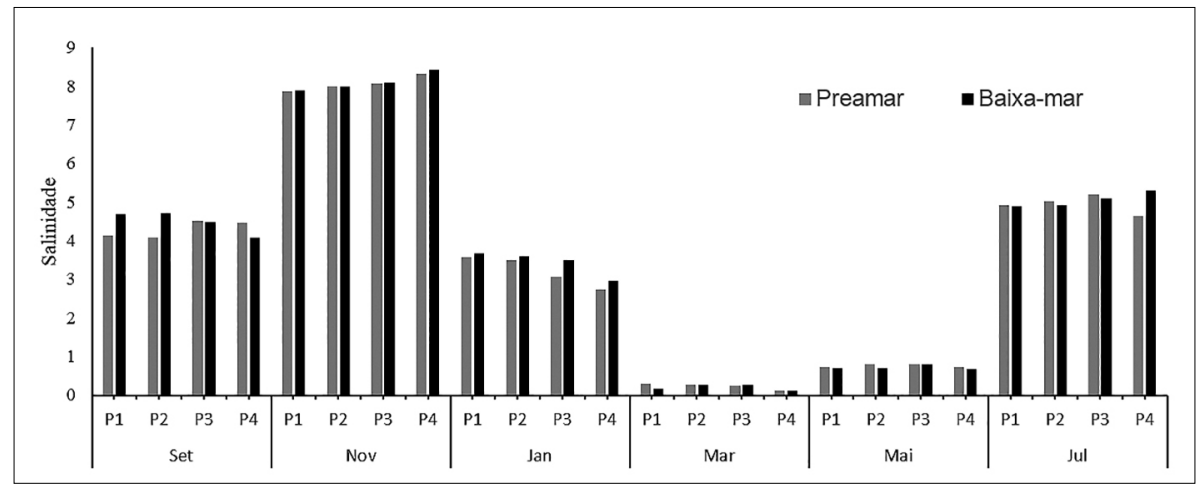

Para o $\mathrm{pH}$, os valores oscilaram entre 5,59 (ponto $\mathrm{P}_{3^{\prime}}$ janeiro de 2012) e 7,90 (ponto $\mathrm{P}_{4^{\prime}}$ setembro de 2011), ambos verificados durante a preamar. O valor da média do pH foi próximo entre os períodos, 6,28 no período de maior pluviosidade e de 6,89 no de menor pluviosidade.

Outras variáveis com oscilação foram o oxigênio dissolvido e a taxa de saturação de oxigênio dissolvido, o menor valor foi de $4,78 \mathrm{mg} . \mathrm{L}^{-1}$ e $58 \%$ no ponto $\mathrm{P}_{1}$, na maré preamar em novembro de 2011. E o maior valor foi de 10,29 mg. $\mathrm{L}^{-1}$ e $119 \%$ no ponto $\mathrm{P}_{3}$, na baixa-mar em janeiro de 2012.

Os valores médios de oxigênio dissolvido também foram próximos entre os períodos, 7,55 mg. $\mathrm{L}^{-1}$ (taxa de saturação de $87 \%$ ) e de 7,27 mg. $\mathrm{L}^{-1}$ (taxa de saturação de 88,5\%), no período de maior e menor pluviosidade, respectivamente.

Os valores dos sólidos em suspensão oscilaram de $14 \mathrm{mg} . \mathrm{L}^{-1}$, observado no ponto $\mathrm{P}_{3^{\prime}}$ na preamar em setembro 2011, a 189 mg. $\mathrm{L}^{-1}$, no ponto $\mathrm{P}_{1}$, na preamar em março de 2012 (Figura 5). Entre os períodos, a média foi de $46,33 \mathrm{mg} . \mathrm{L}^{-1}$ no período de menor pluviosidade a 92,125 mg. $\mathrm{L}^{-1}$ no de maior pluviosidade (Figura $3 \mathrm{~d}$ ).

Entre as formas nitrogenadas, o N-amoniacal teve seu menor valor de $0,29 \mathrm{mg} . \mathrm{L}^{-1}$ no ponto $\mathrm{P}_{3}$, na preamar em setembro de 2011, e o maior no ponto $\mathrm{P}_{3}$, na baixa-mar, de 1,7 mg. $\mathrm{L}^{-1}$ em março de 2012 (Figura 6). A média de $\mathrm{N}$-amoniacal foi de 0,52 $\mathrm{mg}^{-\mathrm{L}^{-1}}$ para o período de maior pluviosidade e de $0,49 \mathrm{mg} . \mathrm{L}^{-1}$ para o período de menor pluviosidade.

Já o nitrito, forma intermediária entre o N-amoniacal e o nitrato no ciclo do nitrogênio, oscilou de $0,001 \mathrm{mg} . \mathrm{L}^{-1}$ no ponto $\mathrm{P}_{4}$, na baixa-mar em março de 2012, a 0,016 mg.L.-1 no ponto $\mathrm{P}_{3^{\prime}}$ na preamar em novembro de 2011 . Os valores médios foram de $0,001 \mathrm{mg} . \mathrm{L}^{-1} \mathrm{e}$ de $0,007 \mathrm{mg} . \mathrm{L}^{-1}$ nos períodos de maior e menor pluviosidade, respectivamente. 
Para o nitrato, o menor valor, de $0,01 \mathrm{mg}^{\mathrm{L}} \mathrm{L}^{-1}$, foi detectado em vários pontos em setembro de 2011, período de menor pluviosidade; já o seu maior valor foi de $2,07 \mathrm{mg} . \mathrm{L}^{-1}$ no ponto $\mathrm{P}_{3}$, na baixa-mar em março de 2012, período de maior pluviosidade (Figura 7). A concentração média foi de $0,28 \mathrm{mg}$. $\mathrm{L}^{-1}$ no período de menor pluviosidade e de 1,02 mg.L-1 no período de maior pluviosidade (Figura 3e).

Figura 5 - Distribuições dos valores de sólidos em suspensão nos pontos de coletas durante o período estudado

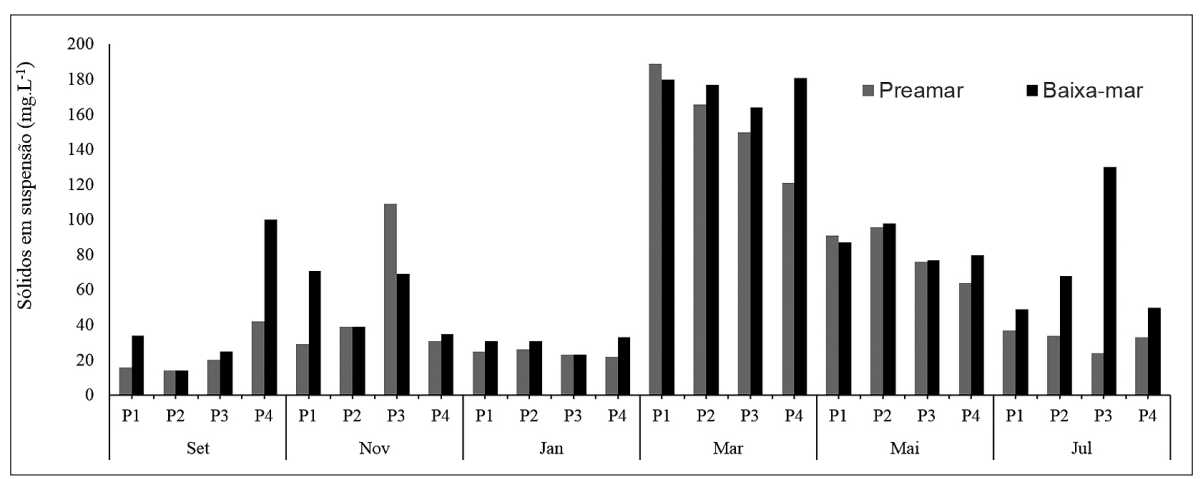

Figura 6 - Distribuições dos valores de N-amoniacal nos pontos de coletas durante o período estudado

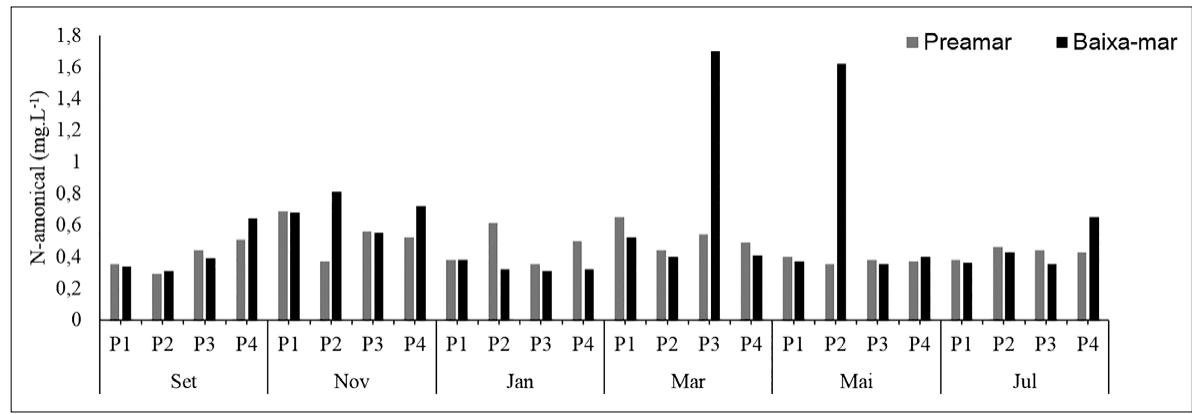

Figura 7 - Distribuições dos valores de nitrato nos pontos de coletas durante o período estudado

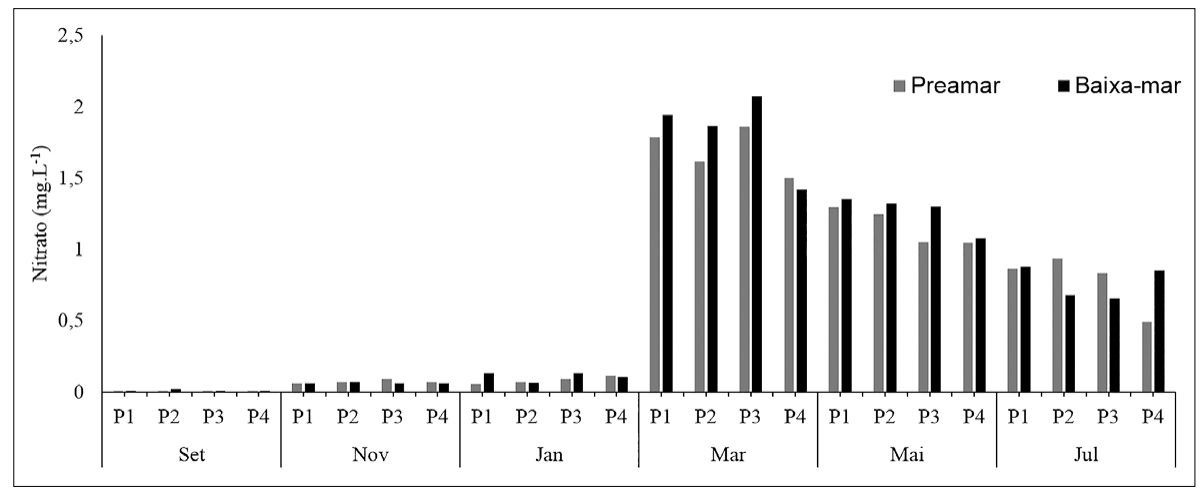

Os valores de fosfato oscilaram de $0,01 \mathrm{mg} . \mathrm{L}^{-1}$, observado em vários pontos em novembro de 2011, período de menor pluviosidade, a 0,29 mg. $\mathrm{L}^{-1}$, na baixa-mar em julho de 2012. O valor médio de fosfato foi de $0,04 \mathrm{mg} . \mathrm{L}^{-1}$ para ambos os períodos.

O silicato teve variações na sua distribuição, seu menor valor foi de $0,16 \mathrm{mg} . \mathrm{L}^{-1}$ no ponto $\mathrm{P}_{1}$, na baixa-mar em setembro de 2011 , e seu maior valor foi de $6,77 \mathrm{mg} . \mathrm{L}^{-1}$ no 
ponto $\mathrm{P}_{3}$, na preamar em março de 2012 (Figura 8). Os valores médios de silicato para os períodos de maior e menor pluviosidade foram de 3,94 mg. $\mathrm{L}^{-1}$ e $1,95 \mathrm{mg}$. $\mathrm{L}^{-1}$, respectivamente (Figura 3f).

Para a clorofila $a$ os valores oscilaram de 0,26 mg. $\mathrm{m}^{3}$ a $14,87 \mathrm{mg} \cdot \mathrm{m}^{3}$, ambos encontrados no ponto $\mathrm{P}_{3}$, na baixa-mar em setembro de 2011 e em julho de 2012, respectivamente. Já o valor médio foi de 2,48 mg. $\mathrm{m}^{3}$ para o período de maior pluviosidade e de 2,89 mg. $\mathrm{m}^{3}$ para o período de menor pluviosidade (Figura 3c).

Figura 8 - Distribuições dos valores de silicato nos pontos de coletas durante o período estudado

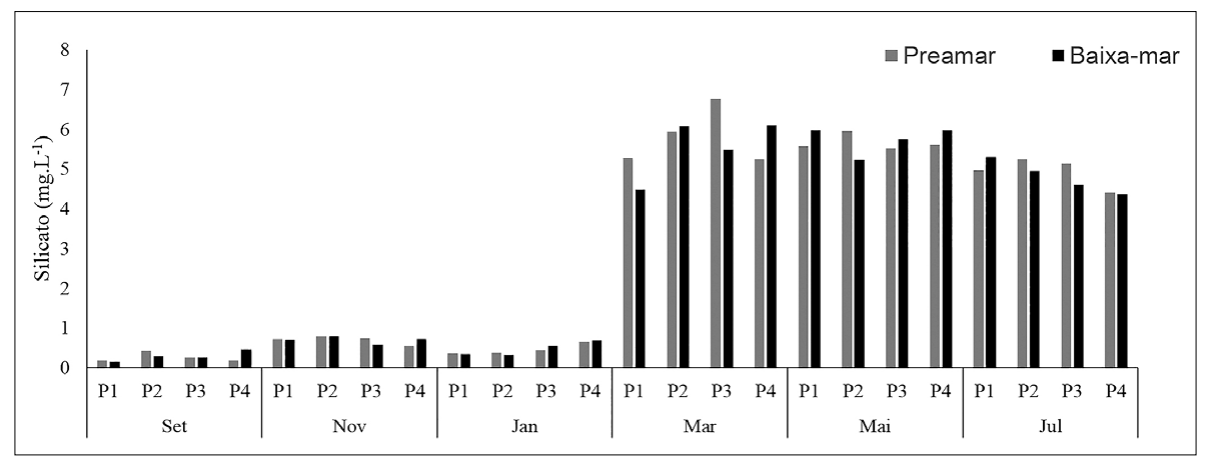

A análise de agrupamento (Figura 9), com relação à variação espaçotemporal dos dados, mostrou que houve apenas formação de dois grupos, onde o primeiro caracterizou uma similaridade entre uma parte das amostras de março que representa o primeiro grupo, porém apenas a amostra da preamar no ponto 04 apresentou maior similaridade com o restante dos dados que representa o segundo grupo.

Figura 9 - Análise de agrupamento realizada com as marés (baixa-mar $=B$, preamar $=P$ ), os meses em que foram realizadas as coletas (janeiro $=\mathrm{J}$, março $=\mathrm{M}$, maio $=\mathrm{MA}$, julho $=\mathrm{JL}$, setembro $=$ $\mathrm{S}$, novembro $=\mathrm{N}$ ) e os pontos de coleta $(01,02,03,04)$ de todos os dados obtidos no estuário Guajará-Mirim durante o período de estudo

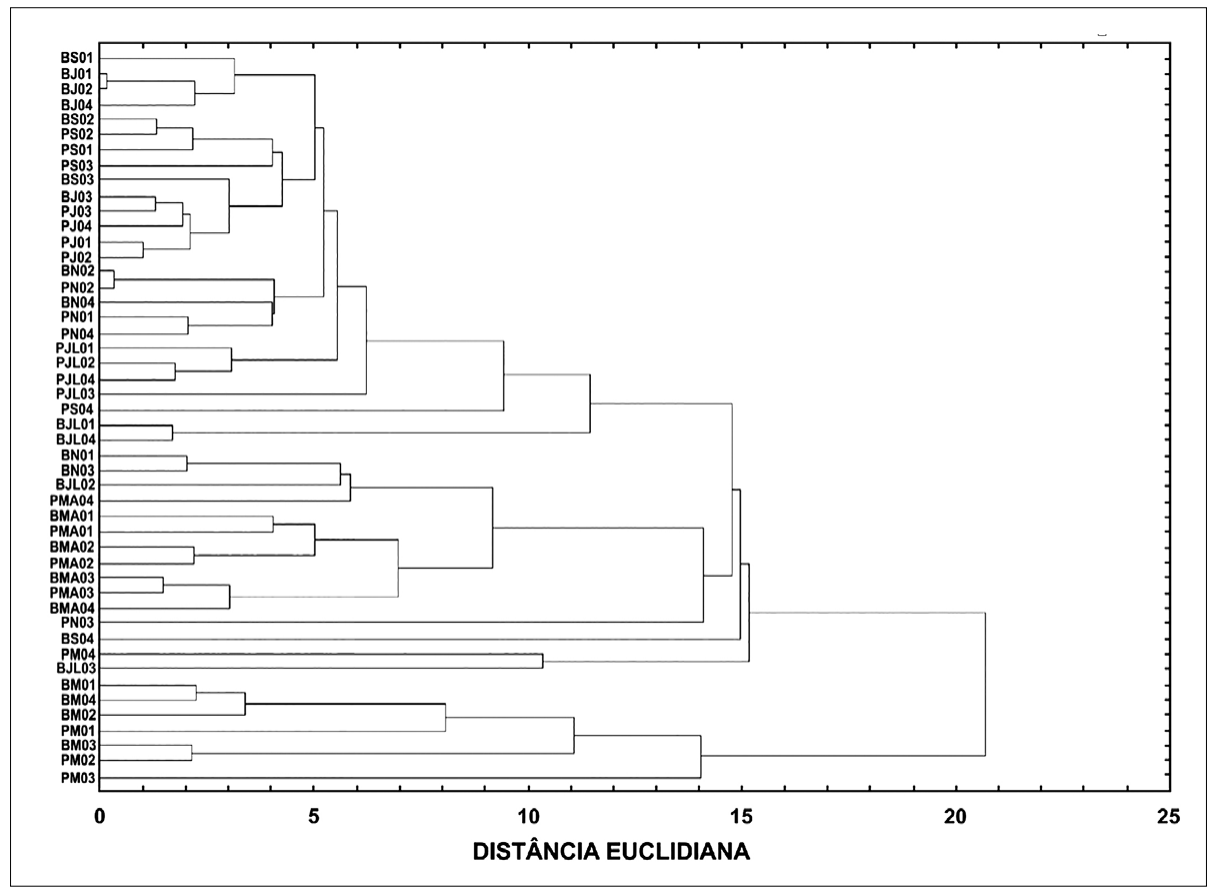


A análise de componentes principais com todos os parâmetros abióticos e clorofila $a$ obtidos nos diferentes pontos de coleta mostra que as duas primeiras componentes (PC1 e PC2) juntas descrevem 63\% da variância original (Tabela I). O eixo 1 (PC1) explicou 41\% da variância total e pode ser interpretado como um contraste entre, de um lado, temperatura, salinidade e clorofila $a$ e, de outro, sólidos em suspensão, silicato e nitrato. Valores positivos e negativos representam, respectivamente, correlação positiva e negativa ao longo do eixo. Esses sinais contrários indicam uma correlação negativa ao longo desse eixo entre esses dois grupos, que são a principal fonte de variação no conjunto de amostras.

Tabela I-Pesos e variância explicada pelas duas primeiras componentes principais da análise dos parâmetros abióticos e clorofila $a$, com dados obtidos no período de estudo. Os valores mais significativos estão em negrito

\begin{tabular}{l|c|c}
\hline Parâmetros & Eixo 1 & Eixo 2 \\
\hline Temperatura $\left({ }^{\circ} \mathrm{C}\right)$ & $\mathbf{0 , 7 2}$ & 0,05 \\
\hline Salinidade & $\mathbf{0 , 8 0}$ & $\mathbf{0 , 5 5}$ \\
\hline $\mathrm{pH}$ & 0,27 & $-0,20$ \\
\hline Oxigênio dissolvido $\left(\mathrm{mg} . \mathrm{L}^{-1}\right)$ & 0,24 & $\mathbf{- 0 , 7 0}$ \\
\hline Sólidos em suspensão $\left(\mathrm{mg}^{-} \mathrm{L}^{-1}\right)$ & $\mathbf{- 0 , 8 2}$ & 0,10 \\
\hline N-amoniacal $\left(\mathrm{mg} . \mathrm{L}^{-1}\right)$ & $-0,28$ & 0,31 \\
\hline Nitrito $\left(\mathrm{mg} \cdot \mathrm{L}^{-1}\right)$ & 0,32 & $\mathbf{0 , 8 4}$ \\
\hline Nitrato $\left(\mathrm{mg} \cdot \mathrm{L}^{-1}\right)$ & $\mathbf{- 0 , 9 6}$ & 0,01 \\
\hline Fosfato $\left(\mathrm{mg} \cdot \mathrm{L}^{-1}\right)$ & $-0,16$ & $-0,26$ \\
\hline Silicato $\left(\mathrm{mg} \cdot \mathrm{L}^{-1}\right)$ & $\mathbf{- 0 , 8 7}$ & 0,05 \\
\hline Clorofila $a\left(\mathrm{mg} \cdot \mathrm{m}^{3}\right)$ & $\mathbf{0 , 5 0}$ & $\mathbf{- 0 , 6 6}$ \\
\hline Variância explicada $\mathbf{( \% )}$ & $\mathbf{4 1}$ & $\mathbf{2 2}$ \\
\hline
\end{tabular}

A temperatura, salinidade e clorofila $a$ mostraram uma alta correlação entre si e inversa com os sólidos em suspensão, nitrato e silicato, o que demonstra que a clorofila $a$ foi favorecida quando ocorreu a diminuição dos sólidos em suspensão na água, e períodos de maior pluviosidade da região favorecem o transporte para águas de sólidos em suspensão oriundos das áreas próximas ao estuário.

Também foi notado que a clorofila $a$ teve uma relação direta com o OD ao longo do eixo 2 (PC2 que explicou 22\% da variância total), o que indica se o processo fotossintético é uma fonte desse gás para o ambiente. No eixo 2, a salinidade e o nitrito tiveram correlação direta entre si, o que indica que a entrada de águas mais salobras renovou a concentração dessa forma nitrogenada. Também nesse eixo, o OD e clorofila $a$ foram relacionados entre si, o que reforça que esse gás é favorecido pelo processo fotossintético.

Os escores para os dados de PC1 e PC2, estratificados de acordo com os períodos de menor e maior pluviosidade, estão plotados nas Figuras 10a e 10b. Pode-se observar uma nítida separação entre os períodos estudados, durante os períodos de menor e de maior pluviosidade. Entre as marés não foi possível visualizar essa separação.

Os escores obtidos pela análise de componentes principais separaram de forma clara os períodos de maior e de menor pluviosidade, ou seja, demonstraram a influência da sazonalidade nas distribuições de temperatura, salinidade, sólidos em suspensão, nitrato, silicato, clorofila $a$, oxigênio dissolvido e nitrito. 
Figura 10 - Escores com todos os dados obtidos em função dos: a) período de menor e maior pluviosidade da região e b) baixa-mar e preamar. Onde: $\mathrm{OD}=$ oxigênio dissolvido, $\mathrm{Chl}-\mathrm{a}=$ clorofila $a, \mathrm{~T}=$ temperatura, $\mathrm{S}=$ salinidade, $\mathrm{SS}=$ sólidos em suspensão, $\mathrm{NO}_{2}^{-}=$nitrito, $\mathrm{NO}_{3}^{-}=$ nitrato, $\mathrm{NH}_{3}+\mathrm{NH}_{4}^{+}=\mathrm{N}$-amoniacal

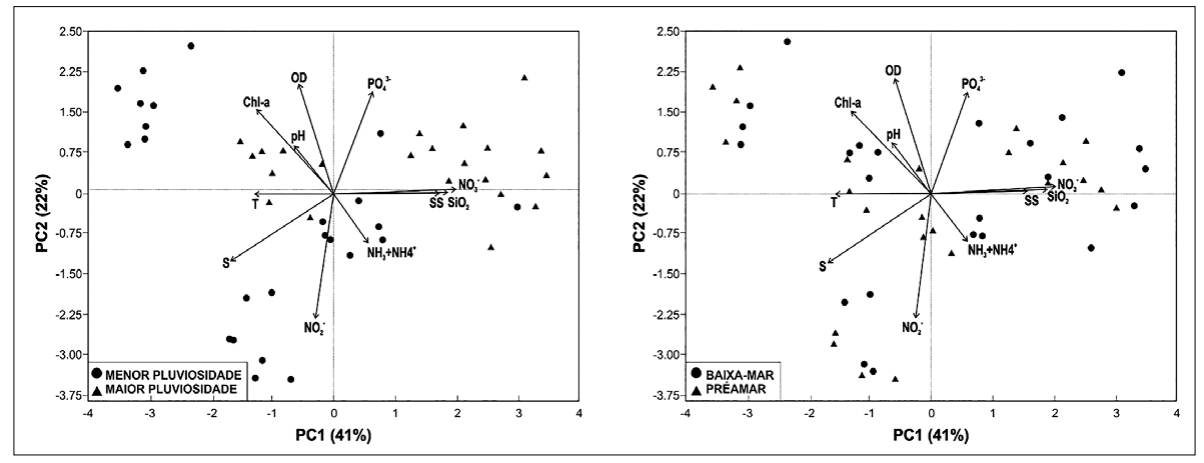

\section{DISCUSSÃO}

O estuário Guajará-Mirim, assim como os estuários da região Norte do Brasil, ou mais regionalmente os pertencentes ao Estuário Amazônico são dominados pela pronunciada periodicidade do ciclo das chuvas na região. O primeiro semestre do ano é conhecido na região como "inverno", com maior quantidade de chuva. No estuário, essa época é caracterizada pelo afastamento das águas mais salinas, de origem oceânica, que são deslocadas para longe da foz pela forte descarga do rio Amazonas. No "verão", com a diminuição da pluviosidade, ocorre o fenômeno inverso e a zona de mistura salina se aproxima da foz Amazônica (Egler \& Schwassmann, 1962; Schwassmann; Barthem \& Carvalho, 1989).

No período de estudo, pôde-se observar que não houve grandes variações nos valores de temperatura superficial da água entre os pontos de coleta e entre as marés. Já entre os períodos, notou-se uma nítida variação, onde a temperatura apresentou uma amplitude de variação de $4,12{ }^{\circ} \mathrm{C}$, com mínima de $26,76{ }^{\circ} \mathrm{C}$ e máxima de $30,88{ }^{\circ} \mathrm{C}$, indicando a forte influência da sazonalidade na distribuição desse parâmetro. Resultados semelhantes foram registrados por Santana (2004) no estuário do rio Marapanim (Pará), onde a temperatura também apresentou uma variação entre os períodos sazonais da região, com mínima de $26,90^{\circ} \mathrm{C}$ e máxima de $30,30^{\circ} \mathrm{C}$, amplitude de $3,40^{\circ} \mathrm{C}$. Sousa et al. (2009) registraram mínima de $26,0^{\circ} \mathrm{C}$ e máxima de $31,3^{\circ} \mathrm{C}$ (amplitude de $5,3^{\circ} \mathrm{C}$ ) no estuário de Taperaçu na Ilha de Canela Bragança (Pará). Miranda et al. (2015) também encontraram pequenas variações de temperatura nas águas da Ilha de Mosqueiro (Pará) entre as marés, com os maiores valores detectados no período menos chuvoso (média de $30,79^{\circ} \mathrm{C}$ ).

Em relação à salinidade, foi observada uma diminuição nos valores durante o período de maior pluviosidade, o que demonstrou a influência do regime pluviométrico da região na distribuição dessa variável, com os valores mais baixos em março e mais elevados no mês de novembro. No período entre marés não foi verificado variabilidade significativa nos teores desse parâmetro no estuário do rio Guajará-Mirim. Os valores de salinidade do estuário em estudo podem ser considerados baixos em relação a outros estuários do nordeste paraense, onde os teores de salinidade se aproximam de 40, durante o período de menor pluviosidade (Sousa et al., 2009; Contente et al., 2007). Essa diminuição ocorre como consequência da distância entre o estuário e o oceano e o aporte fluvial proveniente 
do rio Guajará-Mirim e de seus tributários, tendo como principal o rio Baiacu, que ocorre principalmente no período de maior pluviosidade.

Outro parâmetro abiótico considerado importante é o pH, o qual oscilou entre alcalino e ácido, não mantendo um padrão sazonal completo, pois esse parâmetro se manteve alcalino apenas nas coletas de setembro de 2011; nos demais meses o $\mathrm{pH}$ se manteve abaixo de 7, portanto ácido. Tais valores podem ser remetidos ao aporte fluvial proveniente do rio Guajará-Mirim e seu tributário. Esse parâmetro não teve variações significativas durante os regimes de marés.

Valores diferentes foram encontrados por Cardoso (2008) no estuário do rio GuajaráMirim, onde em todo o período de estudo o $\mathrm{pH}$ permaneceu alcalino, consequência de os pontos de amostragens do referido autor estarem localizados na parte mais externa do estuário, com maior influência marinha. Contudo, de acordo com Miranda et al. (2015), baixos valores de pH para as águas da região amazônica são descritos na literatura (Silva et al., 2011; Alves et al., 2012). Os valores deste trabalho foram comparados com a Resolução Conama $\mathrm{n}^{\mathrm{o}} 357 / 2005$ para águas salobras Classe 1 e os valores de $\mathrm{pH}$ nessa classe estão compreendidos entre 6,5 e 8,5. Esse parâmetro esteve abaixo do limite estabelecido pelo Conama nas coletas de novembro de 2011, janeiro de 2012 e março de 2012. Nos demais meses, o pH se manteve dentro do intervalo compreendido. Contudo, destaca-se que os valores de $\mathrm{pH}$ são esperados para a região de estudo.

De acordo com Santos (2000), no ambiente aquático, o teor de oxigênio dissolvido na superfície se encontra em equilíbrio com o ar atmosférico, ao passo que os processos químicos, resultantes de fenômenos biológicos ou não, promovem um desvio dos valores de saturação para mais ou menos. $\mathrm{O}$ valor efetivo do teor de oxigênio dissolvido é resultado da expressão da interação desses fatores.

As águas estuarinas do rio Guajará-Mirim apresentaram-se bem oxigenadas, talvez pelo fato de a coleta ter sido realizada no período onde havia alta incidência solar, o OD não apresentou variações significativas entre as marés e se mostrou equilibrado entre os períodos de menor e maior pluviosidade. Valores semelhantes foram encontrados por Contente et al. (2007) no estuário do rio Curuçá, no Pará, onde a concentração de oxigênio variou de 7,8 a $8,4 \mathrm{mg} . \mathrm{L}^{-1}$ (período de menor pluviosidade) e de 7,9 a 8,5 mg.L.-1 (período de maior pluviosidade). Macêdo e Costa (1978) classificaram o ambiente estuarino em: zona saturada - com teores acima de 100\%; zona de baixa saturação - com teores entre $50 \%$ e $100 \%$; zona semipoluída - com teores entre $25 \%$ e $50 \%$; zona poluída - com teores abaixo de $25 \%$. Baseado nesse sistema de classificação, verifica-se que o estuário do rio GuajaráMirim se enquadrou como zona de baixa saturação a saturada. As concentrações encontradas estavam acima do valor mínimo estabelecido pela Resolução Conama nº 357/2005, cujo valor é de 5,0 mg. $\mathrm{L}^{-1}$.

Os maiores valores de sólidos em suspensão ocorreram no período de maior pluviosidade, o que já era esperado, pois há o aumento do aporte fluvial na estação chuvosa com a diminuição da salinidade. Segundo Bastos (2002), como o ambiente estuarino apresenta um forte hidrodinamismo e sofre interferência tanto do rio como do mar, é de se esperar que ele apresente, sempre, uma boa quantidade de material em suspensão na água. Entretanto, o regime pluviométrico da região pode provocar variação sazonal nas concentrações desse parâmetro.

Valores elevados de sólidos em suspensão também foram encontrados nas águas da Baía do Guajará e na foz rio Guamá, o que deixa suas águas barrentas, entre 15,1 mg.L-1 e 
233 mg.L-1 (Santos et al., 2014). Águas de aparência barrenta também foram observadas na área de estudo.

A oxidação referente às formas nitrogenadas é responsável pela transformação do N-amoniacal em nitritos, e estes em nitratos, no fenômeno denominado de nitrificação. Segundo Schmiegelow (2004), a distribuição dos principais nutrientes inorgânicos se dá de maneira vertical. Além disso, estes mostram um padrão típico: são geralmente raros em águas superficiais, pois nas camadas superficiais iluminadas o fitoplâncton consome rapidamente todo o nutriente disponível.

Entre as formas nitrogenadas inorgânicas dissolvidas estudadas, foi observado que o $\mathrm{N}$-amoniacal teve as maiores concentrações, seguido do nitrato e do nitrito. Em áreas estuarinas, os aportes fluviais representam uma importante fonte de nutrientes alóctones e matéria orgânica para esses ambientes (Barroso, 2004).

Segundo a Resolução Conama $n^{0} 357 / 2005$, Classe 1 para águas salobras o limite para o nitrito $\left(\mathrm{NO}_{2}\right)$ é de $0,07 \mathrm{mg}$. $\mathrm{L}^{-1}$ como $\mathrm{N}$. Enquanto para o nitrato $\left(\mathrm{NO}_{3}\right)$ e $\mathrm{N}$-amoniacal $\left(\mathrm{NH}_{3}\right)$ é de $0,4 \mathrm{mg}$. $\mathrm{L}^{-1}$ como $\mathrm{N}$. As maiores concentrações de N-amoniacal ocorreram no período de maior pluviosidade, coincidindo com os maiores valores de sólidos em suspensão e OD, e os menores de salinidade. Durante as coletas realizadas em março de 2012 (1,7 mg. $\left.\mathrm{L}^{-1}\right)$ e maio de 2012 (1,62 mg.L $\left.\mathrm{L}^{-1}\right)$ no ponto P3, na maré baixa-mar, foram detectadas as maiores concentrações desse nutriente, o que pode ser relacionado ao fato de esse ponto estar localizado em frente à cidade, que recebe lançamento de efluente doméstico sem tratamento. Em relação aos regimes de marés, não se observou variações significativas, a não ser a mencionada anteriormente.

Os valores de $\mathrm{N}$-amoniacal quando comparados com a Resolução do Conama $\mathrm{n}^{\mathrm{o}}$ $357 / 2005$ estiveram em sua maioria acima do valor estabelecido, dando destaque para os pontos citados acima.

Os valores de nitrito estiveram praticamente ausentes no período de maior pluviosidade, já no período de menor pluviosidade houve um ligeiro aumento na concentração dessa forma nitrogenada, que foi causada pela entrada de águas salinas oriundas do período onde águas salinas adentram o estuário carregando consigo nutrientes como o nitrito, comportamento o qual também foi observado por Monteiro, El-Robrini e Alves (2015) no estuário do rio Paracuari. Contudo, não representa um perigo para o estuário, pois, segundo a Resolução do Conama n⿳3 357/2005, na Classe 1 o limite de nitrito para águas salobras é de 0,07 mg.L-1 .

As concentrações de nitrato foram maiores em meados do período chuvoso e no início do período seco. O nitrato é a última etapa da oxidação do ambiente no meio, sendo essa forma, então, a mais estável. Em relação à variação de maré, essa forma nitrogenada não apresentou mudanças expressivas.

Pereira Filho et al. (2001) estudaram o estuário do rio Camboriú em Santa Catarina, ambiente bastante impactado devido ao lançamento de efluentes da estação de tratamento do município e também por esgotos clandestinos, e encontraram concentrações médias de nitrato de 173,6 mg. $\mathrm{L}^{-1}$, com valor máximo alcançando $403 \mathrm{mg} . \mathrm{L}^{-1}$. Nota-se que as concentrações de nitrato encontradas no presente trabalho são inferiores quando comparadas com um ambiente altamente impactado por lançamento de efluentes.

As concentrações de nitrato, quando comparadas com a Resolução do Conama $n^{\circ}$ $357 / 2005$, encontram-se acima do valor estabelecido nas coletas realizadas nos meses de março, maio e julho de 2012; nos demais meses, os valores se encontram abaixo do valor estipulado por essa resolução. 
Em conjunto com o nitrogênio, o fósforo representa um elemento de importância estrutural para os organismos e para a conversão de energia para todo o sistema biológico. Esses nutrientes também representam um fator limitante para a produção primária pela comunidade fitoplanctônica (Azevedo \& Braga, 2011), constituindo um dos principais fatores de estímulo para o surgimento de um ambiente eutrófico. Por ser também um importante nutriente, pode contribuir para o crescimento excessivo de algas. Os valores de fosfato para o estuário do rio Guajará-Mirim se mantiveram equilibrados em ambos os períodos, ou seja, o fosfato não evidenciou sazonalidade. Bastos et al. (2005), em estudos realizados no estuário do rio Una, em Pernambuco, também não observaram sazonalidade nas concentrações de fosfato. Em relação à maré, houve um ligeiro aumento no ponto P4 em julho de 2012; nos demais pontos de coleta, as concentrações de fosfato se mantiveram equilibradas. As baixas concentrações de fosfato, de acordo com Baumgarten, Niencheski e Kuroshima (1995), podem ocorrer por adsorção ao sedimento de parte do fosfato disponível na água, como por floculação de compostos contendo ferro e fósforo, tanto nas frações inorgânicas do material em suspensão (argilas, siltes, óxidos de ferro, manganês ou alumínio) como orgânicas (substâncias húmicas), que passam a ser um grande reservatório de fósforo, resultando em um efeito tampão de aporte de fosfato.

Outro nutriente utilizado pelas microalgas do grupo das diatomáceas e dos silicoflagelados para formação das suas frústulas é o silicato, considerado como o nutriente inorgânico com as maiores concentrações nos ambientes estuarinos (Delgado Noriega et al., 2005) devido aos aportes fluviais. No presente estudo, as concentrações de silicato foram maiores nos meses de março e maio de 2012, ou seja, período de chuva da região. Tais concentrações ainda se mantiveram elevadas no início do período de menor pluviosidade. Enquanto as marés (preamar e baixa-mar), não houve variações significativas nas concentrações do silicato.

As maiores concentrações de clorofila $a$ foram observadas em setembro 2011 e janeiro de 2012; nos demais meses de coleta não houve variações consideráveis entre as marés. Essa variação da clorofila $a$ pode ser associada à diminuição dos valores de sólidos em suspensão na área de estudo. Por meio da análise de componentes principais foi possível observar uma relação inversa entre os dados de clorofila $a$ e sólidos em suspensão, ou seja, como a diminuição dos sólidos em suspensão aumenta a transparência da água, esta última favorece a presença da clorofila $a$, fato também observado no estuário da Lagoa dos Patos e no estuário do rio São Francisco (Gianasi et al., 2011; Melo, 2012).

Comparando-se o estuário do rio Guajará-Mirim com outras áreas estuarinas tropicais, verifica-se que os teores de clorofila não são compatíveis em termos de sazonalidade, como os resultados encontrados na Ilha de Canela em Bragança, no Pará, onde os teores de clorofila seguiram um padrão sazonal com valores médios de $4,67 \mathrm{mg} \cdot \mathrm{m}^{-3}$ durante o período seco e 5,44 mg.m ${ }^{-3}$ no período chuvoso (Sousa et al., 2009). Alves et al. (2012) consideraram as águas do rio Arari, localizado na Ilha de Marajó (Pará), como eutrofizadas, conforme os valores medianos encontrados para clorofila a (mediana de 17,40 mg. $\mathrm{m}^{-3}$ no período chuvoso e de $8,91 \mathrm{mg} \cdot \mathrm{m}^{-3}$ no período menos chuvoso). Ao comparar os valores, observa-se que os valores médios encontrados no presente trabalho foram bem menores.

Os estuários são ambientes considerados ricos em produtividade, com altas concentrações de nutrientes, porém o material em suspensão associado à ação das correntes pode ser considerado um dos fatores controladores da produtividade primária em áreas estuarinas, visto que a transparência da água será afetada. 


\section{CONCLUSÃO}

As distribuições dos parâmetros abióticos e clorofila a no estuário de Guajará-Mirim são influenciadas pelos períodos de maior e menor pluviosidade da região, o que pode ser observado pela análise de componentes principais, que demonstrou a influência da sazonalidade nas distribuições de temperatura, salinidade, sólidos em suspensão, nitrato, silicato, clorofila $a$, oxigênio dissolvido e nitrito.

O N-amoniacal esteve em sua maioria acima do valor estabelecido pela Resolução Conama $\mathrm{n}^{\circ} 357 / 05$, junto com as concentrações de nitrato, o que indica haver necessidade de um monitoramento mais detalhado para avaliar as fontes difusas de poluição existentes nesse estuário, e com isso propor medidas mitigadoras para manter a qualidade da água nesse ambiente tão importante para a população local.

\section{REFERÊNCIAS BIBLIOGRÁFICAS}

Agência Nacional de Águas. Ana. Disponível em http://www.snirh.gov.br/hidroweb/publico/ medicoes_historicas_abas.jsf. Acesso em: 10 jul. 2012.

APHA, AWWA, WEF. Standard methods for the examination of water and wastewater American Public Health Association, Washington, 1995.

Azevedo, J.S. \& Braga, E.S. Caracterização hidroquímica para a qualificação ambiental dos estuários de Santos-São Vicente e Cananeia. Arq. Ciên. Mar, Fortaleza, v. 44, n. 2, p. 52-61, 2011.

Alves, I.C.C.; El-Robrini, M.; Santos, M.L.S.; Monteiro, S.M.; Barbosa, L.P.F. \& Guimarães, J.T.F. Qualidade das águas superficiais e avaliação do estado trófico do rio Arari (Ilha de Marajó, Norte do Brasil). Acta Amazonica, v. 42, n. 1, p. 115-124, 2012.

Barroso, G.F. Development of an evaluation framework for sustainable bivalve aquaculture: a strategic plan approach in Espírito Santo, Brazil. PhD Thesis, Geography, University of Victoria, 229 p., Canadá, 2004.

Bastos, R.B. Variação espaço-temporal da biomassa fitoplanctônica relacionada com parâmetros abióticos no estuário do rio Una (Pernambuco-Brasil). Monografia de graduação, curso de Biologia, Universidade Federal de Pernambuco, 56 p., Recife, 2002.

Bastos, R.B.; Feitosa, F.A.N. \& Muniz, K. Variabilidade espaço-temporal da biomassa fitoplanctônica e hidrologia no estuário do rio Una (Pernambuco-Brasil). Trop. Oceanogr., Recife, v. 33, n. 1, p. 1-18, 2005.

Baumgarten, M.G.Z.; Niencheski, L.F.H. \& Kuroshima, K.N. Qualidade das águas estuarinas que margeiam o município do Rio Grande (RS, Brasil): nutrientes e detergentes dissolvidos. Rev. Atlânt., Rio Grande, v. 17, p. 17-34, 1995.

Cardoso, F.F. Dinâmica da comunidade microfitoplanctônica relacionada com os parâmetros físico-químicos do estuário do rio Guajará-Mirim (Vigia-PA). Dissertação de mestrado, Programa de Pós-Graduação em Ecologia Aquática e Pesca, Universidade Federal do Pará, 76 p., Belém, 2008.

Brasil. Conama, Resolução 357, de 17 de março de 2005. Diário Oficial da República Federativa do Brasil, 23 p., Brasília, 2005. 
Contente, C.T.; Palheta, G.D.A.; Melo, N.F.A.C.; Ramos, C.A.R. \& Paiva, R.S. Variação nictemeral do ictioplâncton no estuário do rio Curuçá (Pará-Brasil), durante os períodos chuvoso e seco. Bol. Téc. Cient. do Cepnor, Belém, v. 7, n. 1, p. 27-40, 2007.

Delgado Noriega, C.; Muniz, K.; Araújo, M.C.; Travassos, R.K. \& Neumann-Leitão, S. Fluxos de nutrientes inorgânicos dissolvidos em um estuário tropical - Barra das Jangadas-PE, Brasil. Trop. Oceanogr., Recife, v. 33, n. 2, p. 133-145, 2005.

Egler, W.A. \& Schwassmann, H.O. Limnological studies in the Amazon Estuary. Bol. Mus. Para. Emílio Goeldi, Belém, nova série, n. 1, p. 2-25, 1962.

Feitosa, F.A.N.; Nascimento, F.C.R. \& Costa, K.M.P. Distribuição espacial e temporal da biomassa fitoplanctônica relacionada com parâmetros hidrológicos na Bacia do Pina (Recife-PE). Trop. Oceanogr., Recife, v. 2, n. 2, p. 1-13, 1999.

Gianasi, B.L.; Oliveira, A.O.; Filho, W.P. \& Copertino, M.S. Caracterização espectral da água e da vegetação aquática submersa no estuário da Lagoa dos Patos (RS, Brasil), p. 70517058, in Anais XV Simpósio Brasileiro de Sensoriamento Remoto - SBSR, 7051 p., Curitiba, 2011.

Governo do Pará. Conheça o Pará-Vigia. Disponível em: https://vigia.pa.gov.br/. Acesso: 5 jul. 2011.

Grasshoff, K.; Ehrhardt, M. \& Kremling, K. Methods of seawater analysis. 2. ed., Flórida: Verlage Chemie, 417 p., 1983.

Hammer, Ø.; Harper, D.A.T. \& Ryan, P.D. PAST: paleontological statistics software package for education and data analysis. Palaeontol. Electr., v. 4, p. 1-9, 2001.

Huang, X.P.; Huang, L.M. \& Yue, W.Z. The characteristics of nutrients and eutrophication in the Pearl River estuary, South China. Mar. Pollut. Bul., v. 47, n. 1-6, p. 30-6, 2003.

Legendre, P. \& Legendre, L. Numerical Ecology, second ed, Amsterdam: Elsevier Science, 1006 p., 1998

Lima, M.W;Santos, M.L.S.;Melo, N.F.A.;Faial, K.C.F.; Lima, M.O. \& Nunes, D.M. Distribuição espaço-temporal dos metais $\mathrm{Ba}, \mathrm{Na}, \mathrm{K}, \mathrm{Mn}$ e Ca nos sedimentos de fundo do estuário Furo da Laura, Amazônia Oriental, Brasil. Bol. Téc. Cient. do Cepnor, v. 15, n. 1, p. 15-22, 2015.

Macêdo, S.J.; Melo, H.N.S. \& Costa, K.M.P. Estudos ecológicos da região de Itamaracá, Pernambuco-Brasil. Condições Hidrológicas do Estuário do Rio Botafogo. Trop. Oceanogr., Recife, v. 17, n. 1, p. 346-368, 1982.

Metzler, P.M.; Glibert, P.M.; Gaeta, S.A. \& Ludlam, J.M. New and regenerated production in the South Atlantic off Brazil. Deep-Sea Res. I, v. 44, n. 3, p. 363-34,1997.

Miranda, M.V.T.; Santos, M.L.S.; Pereira, J.A.R. \& Mesquita, K.F.C. Índices de qualidade da água da Ilha de Mosqueiro-PA. Revista DAE, v. jan.-abr., p. 74-81, 2015.

Monteiro, S.M.; El-Robrini, M. \& Alves, I.C.C. Dinâmica sazonal de nutrientes em estuário Amazônico. Mercator, v. 14, n. 1, p. 151-162, 2015.

Melo, E.R. Processos hidrodinâmicos e implicações na carga de nutrientes no estuário do rio São Francisco de corrente das reduções de vazões. Dissertação de mestrado em Meteorologia, Universidade Federal de Alagoas, 105 p., Maceió, 2017.

Penney, R.W; Mackenzie, C.H. \& Mills, T.J. Assessment of the particulate food supply available for mussel (Mytilus spp.) farming in a semi-enclosed orthern Inlet. Est., Coast. and Shelf Sci., v. 53, p. 107-121, 2001. 
Pereira-Filho, J.; Schettini, C.A.F.; Rörig, L. \& Siegle, E. Intratidal variation and net Transport of Dissolved Inorganic Nutrients, POC and Chlorophyll a in the Camboriú River Estuary, Brazil. Est., Coast. and Shelf Sci., v. 53, p. 249-257, 2001.

Santana, D.S. Composição florística e variação espaço-temporal dos parâmetros ambientais e da biomassa fitoplanctônica do estuário do rio Marapanim (Pará, Brasil). Dissertação de mestrado, Programa de Pós-Graduação em Ecologia de Ecossistemas Costeiros e Estuarinos, Universidade Federal do Pará, 113 p., Bragança, 2004.

Santos, M.L.S. Influência dos rios Amazonas e Pará sobre a biomassa fitoplanctônica. Dissertação de mestrado, Programa de Pós-Graduação em Oceanografia, Universidade Federal de Pernambuco, 92 p., Recife, 2000.

Santos, M.L.S.; Holanda, P.; Pereira, I.; Rodrigues, S.; Pereira, J.A.R. \& Mesquita, K. Influência das condições da maré na qualidade de água do rio Guamá e Baía do Guajará. Bol. Téc. Cient. do Cepnor, Belém, v. 14, n. 1, p. 17-25, 2014.

Peres-Neto, P.R.; Jackson, D.A. \& Somers, K.M. Giving meaningful interpretation to ordination axes: assessing loading significance in principal component analysis. Ecology, v. 84, p. 2347-2363, 2003.

Peres-Neto, P.R.; Jackson, D.A. \& Somers, K.M. How many principal components? stopping rules for determining the number of non-trivial axes revisited. Comput. Stat. Data Anal., v. 49, p. 974-997, 2005.

Schmiegelow, J.M.M. O planeta azul: uma introdução às Ciências Marinhas. Rio de Janeiro: Interciência, 202 p., 2004.

Schwassmann, H.O.; Barthem, R.B. \& Carvalho, M.L.A. Note on the seasonally shifting zone of high primary production in the Baya of Marajó. Pará. Brazil. Act. Bot. Bras., São Paulo, v. 2, n. 1, p. 165-174, 1989.

Silva, A.C.; Mangas, A.P.; Palheta, G.D. \& Melo, N.F.A.C. Variação intermareal na composição do ictioplâncton no estuário do rio Guajará-Mirim (Vigia de Nazaré-Pará) em período de alta pluviosidade. Bol. Téc. Cient. do Cepnor, Belém, Pará, v. 11, n. 1, p. 21-32, 2011.

Sousa, E.B.; Costa, V.B.; Pereira, L.C.C. \& Costa, R.M. Variação temporal do fitoplâncton e dos parâmetros hidrológicos da zona de arrebentação da Ilha Canela (Bragança, Pará, Brasil). Act. Bot. Bras., v. 23, n. 4, p. 1084-1095, 2009.

Strickland, J.D.H. \& Parsons, T.R. A practical handbook of seawater analysis. Bull. Fish. Res. Bd., Canadá, 311 p., 1972.

Teixeira, C. Introdução aos métodos para medir a produção primária do fitoplâncton marinho. Bol. Inst. Oceanog., São Paulo, v. 22, p. 59-92, 1973.

Troussellier, M.; Got, P.; Bouvy, M.; Moboup, M.; Arfi, R.; Lebihan, F.; Monfort, P.; Corbin, D. \& Bernard, C. Water quality and health status of the Senegal River estuary. Mar. Pollut. Bul., v. 48, p. 852-862, 2004.

Unesco. International Oceanographic Tables. Wormly, v. 2, 141 p., 1973. 